\title{
Climatic effects on regime shifts in lakes: A reply
}

In a recent study (Scheffer et al. 2001) we showed that spring and summer temperatures of a Dutch lake are strongly correlated to the NAO index of the previous winter and that the timing of clear-water phases in The Netherlands and Central Europe is also correlated to this climatic oscillation. Although this created no dispute, another more counterintuitive result of our analysis raised doubts (Jeppesen et al. 2003; Van Donk et al. 2003): we found that the probability for a spring clear-water phase in Dutch lakes was higher after winters with a higher NAO index, suggesting a positive effect of a mild winter and spring on the chances for a spring clear-water phase.

\section{Management effects}

The main point in both comments is that the NAO correlation may be an artifact of correlated lake management effects. Indeed, all Dutch lakes have been managed over the past decades in order to reduce their chlorophyll level, and lakes with lower average chlorophyll levels are known to have systematically higher chances of having clear water phases (CWPs) (Scheffer et al. 1997). Therefore, we used multiple logistic regression with not only the NAO index but also the average annual chlorophyll concentration as independent variables. However, the authors argue that although summer chlorophyll may be a good surrogate for nutrient status, it should not be used to correct for biomanipulation effects, as biomanipulation 'often results in CWPs that do not remain stable through the whole summer.' While CWPs in some biomanipulated lakes may indeed be short lived, this is actually the rule in most lakes rather than a typical result of biomanipulation (Sommer et al. 1986). We agree that it would be impossible to remove the effect statistically by including chlorophyll in the regression if biomanipulation would tend to let CWPs occur at higher average summer chlorophyll levels. However, this seems unlikely and is not suggested in either of the two references provided by Van Donk et al. Thus, although one may never be able to properly 'remove' confounding effects in multiple regressions, the use of average chlorophyll as a proxy for management effects seems a rather appropriate choice.

\section{Statistical robustness}

Certainly, statistics remain tricky and it is a good idea to check the robustness of the outcome. However, loss of significance after removing $64 \%$ of the clear-water phases, as was accomplished by Van Donk et al., is not surprising, as it simply leaves little data at all. We briefly checked that result by removing $64 \%$ of the cases at random 20 times, a process that yielded nonsignificant results $(P>0.10)$ of the NAO relation in the regression in 18 out of these 20 cases. To further explore the robustness of our results we selectively removed groups of lakes that Van Donk et al. marked as suspicious (Table 1), and to explore whether our results are robust against the choice of a specific cut-off level used, we also checked the effect of allowing only those dips in chlorophyll $a$ that were below $25 \%$ of the average chlorophyll concentration of that lake-year qualify as clear-water phases (Table 2). Significance was invariably maintained, and in addition, the slope of the NAO effect was remarkably stable against all of these manipulations. We do agree, however, that different lake-years cannot really be considered independent, which may have inflated the significance of our results. With respect to plankton, 'memory' for previous

\section{Konstanzer Online-Publikations-System (KOPS)}

URL: http://www.ub.uni-konstanz.de/kops/volltexte/2007/3831/

URN: http://nbn-resolving.de/urn:nbn:de:bsz:352-opus-38312 
Table 1. Multiple logistic regressions on subsets of lakes with presence of clear-water phase (CWP) defined as dip deeper of the average chlorophyll level below $5 \mathrm{mg} \mathrm{L}^{-1}$ as dependent variable and average chlorophyll concentration and NAO winter index as independent variables.

\begin{tabular}{|c|c|c|c|c|}
\hline & Reason for excluding lakes & $\begin{array}{l}\text { Number } \\
\text { of CWP }\end{array}$ & $\begin{array}{l}\text { Significance } \\
\text { NAO }\end{array}$ & $\begin{array}{l}\text { Slope } \\
\text { NAO }\end{array}$ \\
\hline Total set & None & 42 & 0.036 & 0.32 \\
\hline $\begin{array}{l}\text { All biomanipulated and nutrient-treated } \\
\text { lakes removed }\end{array}$ & $\begin{array}{l}\text { Biomanipulation or nutrient } \\
\text { reduction }\end{array}$ & 30 & 0.076 & 0.32 \\
\hline Volkerak and Zoommeer excluded & Freshening & 32 & 0.100 & 0.26 \\
\hline Haringvliet excluded & Riverine & 37 & 0.062 & 0.29 \\
\hline
\end{tabular}

years may be limited (Cottingham et al. 1997). Indeed, if one corrects for generation time, the period between two winters for phytoplankton is comparable to the period between two glacial periods for forest succession (Reynolds 1993), which indicates that for plankton, two consecutive years are rather independent. Nonetheless, other components of the system obviously have a longer memory.

\section{Model analysis}

We now turn to the interpretation of the model results. A reanalysis of the model (Van Donk et al. 2003) confirmed the effect of temperature on timing of CWPs, but it indicated that the effect on the critical fish density needed to suppress a CWP was smaller than originally reported. We rechecked and we agree. This mistake illustrates that one may accept outcomes that are in line with pre-existing ideas too easily. To explore this point further, we examined the model again over a wide parameter range, separating the effects of average temperature from those of the seasonal amplitude and fish reproduction. This analysis (not shown) indicates that, although the positive effect of temperature on the occurrence of spring CWPs may be small in the default parameter setting, the phenomenon is robust in the sense that it actually occurs in a stronger form over a range of other parameter settings.

Obviously, our model, like any minimal model, merely shows the potential implications of a very limited subset of the mechanisms operating in the field. Although in this case the subset appears sufficient to generate a range of realistic patterns of seasonal plankton dynamics (Scheffer et al. 1997), many potentially important aspects are left out. One obvious limitation is the fact that fish (unlike plankton) are not modeled dynamically. Thus, while abundance of plankton in the model can respond in abundance to temperature, fish only respond through increased consumption rates. This seems acceptable for predicting how abnormally warm winter and spring conditions could affect CWPs. However, the model should clearly not be used for predicting the effects on summer dynamics, as fish reproduction and early growth come into play here, and these aspects depend upon temperature.

\section{Opposite spring and summer effects}

This brings us to what should perhaps be the central point of the discussion. Most likely, it was the counterintuitiveness of our result, which invoked the authors of the comments to dig deeper in the work. But should we really be surprised to see positive effects of temperature on CWPs? Numerous detailed studies actually confirm that spring biomass of Daphnia tends to be higher in years with higher water temperatures and higher NAO indices (Gerten and Adrian 2000; Straile 2000; Straile and Adrian 2000; Benndorf et al. 2001; Straile 2002). A possible reason for confusion is the fact that summer plankton responds to NAO conditions in a manner rather opposite to that exhibited in spring plankton dynamics: mild winters and springs tend to be linked to relatively low Daphnia numbers and high algal biomass in summer (Scheffer et al. 1992; Güss et al. 2000; Rooney and Kalff 2000; Benndorf et al. 2001). A positive effect of temperature on the summer biomass of young-of-the-year fish suppressing summer Daphnia (Benndorf et al. 2001; Jeppesen et al. 2002) seems a likely cause for such patterns. The opposite spring and summer effects are nicely illustrated by an analysis of a long-term data set from the German Bautzen Reservoir, where high daphnid biomass during spring associated with a high NAO index was actually found to be the best single predictor for low Daphnia abundance in summer (Benndorf et al. 2001). Thus, part of the confusion may be attributable to the fact that mild winters tend to lead to high

Table 2. Multiple logistic regressions on subsets of lakes with presence of clear-water phase (CWP) defined as dip deeper than $25 \%$ of the average chlorophyll level as dependent variable and average chlorophyll concentration and NAO as independent variables.

\begin{tabular}{llcc}
\hline \hline & & Number & Significance \\
& Reason for excluding lakes & of CWP & $\begin{array}{c}\text { Slope } \\
\text { NAO }\end{array}$ \\
\hline Total set & None & 36 & 0.005 \\
All biomanipulated and nutrient-treated & Biomanipulation or nutrient & & 0.34 \\
$\quad$ lakes removed & reduction & 26 & 0.015 \\
Volkerak and Zoommeer excluded & Freshening & 27 & 0.062 \\
Haringvliet excluded & Riverine & 33 & 0.012 \\
\hline
\end{tabular}


summer algal biomass but at the same time promote spring CWPs.

\section{Long-term climate effects}

With respect to long-term effects of climatic warming, the most important regime shift in shallow lakes is probably not the one from absence to presence of a spring clear-water phase but rather the more dramatic shift from an overall turbid regime without submerged vegetation to a clear regime dominated by submerged macrophytes (Scheffer et al. 1993a). Jeppesen et al. (2003) bring up several observations on nutrients, fish, and macrophytes, suggesting that climatic warming would probably favor a turbid state in the long run. Here, we balance their view with some additional information, suggesting that warmer climate may rather favor a macrophyte-dominated state. Jeppesen et al. (2003) argue that higher internal nutrient loading from sediment decomposition will enhance algal biomass in warm years. Although there is good evidence for this mechanism, it may be a shortterm effect, as the pool that can be decomposed will gradually disappear if warm conditions persist. Effects of climatic change on external nutrient loading are perhaps more important in the long run, but studies on this topic to date have produced rather contradictory results (George 2000; Monteith et al. 2000; Weyhenmeyer 2001; Straile et al. 2003). A hint of the effects of long-term climate change on trophic cascades could be inferred, as suggested by Jeppesen et al. (2003), from the observation that top-down control of zooplankton increases toward lower latitudes because of the continuous reproduction of fish (Dumont 1994). However, substantial increases in temperature may be required to push temperate lakes to a continuously reproducing fish community, as found in (sub)tropical climate zones.

By contrast, several experimental studies indicate that even a moderate increase in temperature can strongly stimulate the growth of aquatic plants (Barko and Smart 1981; Barko et al. 1982; Spencer 1986). Also, field studies suggest positive effects of warming on aquatic vegetation performance. For instance, submerged plant biomass doubled in warm parts of a North Carolina cooling pond (Grace and Tilly 1976); the standing stock of a Ceratophyllum vegetation in an intensively followed Dutch lake was exceptionally low after a cold winter (Best and Dassen 1987); and eelgrass communities have been found to reach higher biomass production in a warm El Niño year (Nelson 1997). Importantly, increased aquatic vegetation may occur despite higher summer turbidity in warm years, suggesting that a positive effect of temperature can override negative effects of reduced summer light availability. For instance, analysis of a 20-years' time series of vegetation distribution in six Dutch lakes shows that warm years tend to be more turbid, but also have more extensive plant beds (Scheffer et al. 1992), and simulations with a plant growth model indicate that the observed variations in temperature are indeed a plausible explanation (Scheffer et al. 1993b). Similarly, a study in five Canadian lakes showed higher turbidity, but also a 45-1,160\% increase in whole-lake macrophyte biomass in a 1998 as compared to the cooler 1997, leading the authors to speculate that cli- mate change may lead to greater biomass and distribution of macrophytes (Rooney and Kalff 2000).

In summary, our results appear remarkably robust against a variety of manipulations, and our use of chlorophyll as an additional explanatory variable seems an appropriate way to prevent confounding effects of lake management. However, the significance of our results may have been inflated by considering different lake-years as independent. Importantly, a range of empirical studies confirms our assertion that warm winters and springs tend to boost spring zooplankton, although the pattern tends to be reversed in summer, when strong young-ofthe-year development leads to rather more turbid conditions in warm years. The implications of long-term climate change remain hard to foresee. However, various lines of evidence are in line with our suggestion that moderate warming may promote a regime shift to a macrophyte-dominated state in temperate shallow lakes. Certainly, there is a need to test the disputed effects of the NAO on other data sets. While Jeppesen et al. (2003) do so, their data set (like ours) has its limitations. Obviously, a large-scale experimental approach in which management experiments are conducted in low-NAO years and the study of the behavior of manipulated and nonmanipulated lakes when the NAO changes would combine to provide the best solution to the debate.

Marten Scheffer

Department of Aquatic Ecology and

Water Quality Management

Agricultural University, Wageningen

Wageningen, The Netherlands

Dietmar Straile

Limnologisches Institut

Universität Konstanz

Konstanz, Germany

Egbert H. van Nes

Department of Aquatic Ecology and

Water Quality Management

Agricultural University, Wageningen

Wageningen, The Netherlands

Harry Hosper

RIZA

P.O. Box 17

NL-8200 AA Leilystad

The Netherlands

\section{References}

BARKo, J. W., D. G. HARdin, AND M. S. MatThews. 1982. Growth and morphology of submersed fresh water macrophytes in relation to light and temperature. Can. J. Bot. 60: 877-887.

- AND R. M. SMART. 1981. Comparative influences of light and temperature on the growth and metabolism of selected submersed fresh water macrophytes. Ecol. Monogr. 51: 219-236.

Benndorf, J., J. Kranich, T. Mehner, And A. Wagner. 2001. Temperature impact on the midsummer decline of Daphnia galeata: An analysis of long-term data from the biomanipulated Bautzen Reservoir (Germany). Freshwat. Biol. 46: 199211. 
Best, E. P. H., AND J. H. DASSEN. 1987. Biomass stand area primary production. Characteristics and oxygen regime of the Ceratophyllum demersum L. population in Lake Vechten, The Netherlands. Arch. Hydrobiol. 76: 347-368.

Cottingham, K. L., S. E. Knight, S. R. Carpenter, J. J. Cole, M. L. Pace, AND A. E. Wagner. 1997. Response of phytoplankton and bacteria to nutrients and zooplankton: A mesocosm experiment. J. Plankton Res. 19: 995-1010.

Dumont, H. J. 1994. On the diversity of the cladocera in the tropics. Hydrobiologia 272: 27-38.

GeORGE, D. G. 2000. The impact of regional-scale changes in the weather on the long-term dynamics of Eudiaptomus and Daphnia in Esthwaite Water, Cumbria. Freshwat. Biol. 45: 111-121.

Gerten, D., AND R. Adrian. 2000. Climate-driven changes in spring plankton dynamics and the sensitivity of shallow polymictic lakes to the North Atlantic Oscillation. Limnol. Oceanogr. 45: $1058-1066$.

Grace, J. B., AND L. J. Tilly. 1976. Distribution and abundance of submerged macrophytes, including Myriophyllum spicatum L. (Angiospermae), in a cooling reservoir. Arch. Hydrobiol. 77: 475-487.

Güss, S., D. Albrecht, H. J. Krambeck, D. C. Muller-NavarRA, AND H. Mumm. 2000. Impact of weather on a lake ecosystem, assessed by cyclo-stationary MCCA of long-term observations. Ecology 81: 1720-1735.

Jeppesen, E., M. SøndergaArd, AND J. P. Jensen. 2003. Climate warming and regime shifts in lake food webs-some comments. Limnol. Oceanogr. 48: 1346-1349.

Monteith, D. T., C. D. Evans, And B. Reynolds. 2000. Are temporal variations in the nitrate content of UK upland freshwaters linked to the North Atlantic Oscillation? Hydrological Processes 14: 1745-1749.

Nelson, T. A. 1997. Interannual variance in a subtidal eelgrass community. Aquat. Bot. 56: 245-252.

REYNOLDS, C. S. 1993. Scales of disturbance and their role in plankton ecology. Hydrobiologia 249: 157-171.

ROONEY, N., AND J. KALFF. 2000. Inter-annual variation in submerged macrophyte community biomass and distribution: The influence of temperature and lake morphometry. Aquat. Bot. 68: $321-335$.

Scheffer, M., A. H. Bakema, AND F. G. Wortelboer. 1993a. MEGAPLANT - a simulation model of the dynamics of submerged plants. Aquat. Bot. 45: 341-356.
- M. R. De Redelijkheid, AND F. Noppert. 1992. Distribution and dynamics of submerged vegetation in a chain of shallow eutrophic lakes. Aquat. Bot. 42: 199-216.

- S. H. Hosper, E. Jeppesen, M. L. Meijer, And B. Moss. 1993b. Alternative equilibria in shallow lakes. Trends Ecol Evol. 8: 275-279.

—, S. Rinaldi, Y. A. Kuznetsov, and E. H. Van Nes. 1997. Seasonal dynamics of Daphnia and algae explained as a periodically forced predator-prey system. Oikos 80: 519-532.

- D. Straile, E. H. Van Nes, and H. Hosper. 2001. Climatic warming causes regime shifts in lake food webs. Limnol. Oceanogr. 46: 1780-1783.

Sommer, U., Z. M. Gliwicz, W. LAmpert, AND A. DunCAN. 1986. The Plankton Ecology Group model of seasonal succession of planktonic events in fresh waters. Arch. Hydrobiol. 106: 433472.

Spencer, D. F. 1986. Early growth of Potamogeton pectinatus L. in response to temperature and irradiance: Morphology and pigment composition. Aquat. Bot. 26: 1-8.

STRAILE, D. 2000. Meteorological forcing of plankton dynamics in a large and deep continental European lake. Oecologia 122: $44-50$.

- 2002. North Atlantic Oscillation synchronizes food-web interactions in central European lakes. Proc. R. Soc. Lond. B 269: 391-395.

- AND R. AdRIAN. 2000. The North Atlantic Oscillation and plankton dynamics in two European lakes-two variations on a general theme. Global Change Biol. 6: 663-670.

, D. M. Livingstone, G. A. Weyhenmeyer, and D. G. GEORGE. 2003. The response of freshwater ecosystems to climate variability associated with the North Atlantic Oscillation, p. 263-279. In J. W. Hurrell, Y. Kushnir, G. Ottersen, and M. Visbeck [eds.], The North Atlantic Oscillation, AGU monographs.

Van Donk, E., L. Santamaria, And W. M. MooiJ. 2003. Climate warming causes regime shifts in lake food webs: A reassessment. Limnol. Oceanogr. 48: 1350-1353.

WeYHENMEYER, G. A. 2001. Warmer winters: Are planktonic algal populations in Sweden's largest lakes affected? Ambio 30: $565-571$. 